\title{
The asynchronous growth and movement reconstruction of the early molting animals
}

\section{Tian Lan ( $\sim$ lantianing@sina.com )}

Guizhou University

Research article

Keywords: Epithelium, Cell mechanics, asynchronous growth, movement, Ecdysozoa

Posted Date: August 1st, 2020

DOI: https://doi.org/10.21203/rs.3.rs-44294/v1

License: (a) (i) This work is licensed under a Creative Commons Attribution 4.0 International License. Read Full License 


\section{Abstract}

Epithelium is one of the basic types of animal tissue, in which tissue boundaries are the physical barriers to separate adjust cell clusters. However, tissue boundary in cellular level can hardly found in the fossil records. Here I focus on the growth and movement patterns of the early Ecdysozoa being through quantifying forces in cellular level of the epithelium of two worms from the early Cambrian and Ordovician period. The epithelium cells (might be but not necessarily represent the biological cell) separate adjust body ring of the early Ecdysozoa indicates a precise morphological patterning in cellular level has been established in the early Cambrian. The forces distribution patterns on the body ring suggest the boundary cells are contribute to maintain pressure gradient among rings which are the building blocks of the movement pattern of the worm. The active tension field of the worms plates though ontogenetic trajectory while epithelium cells are in the steady state indicate these molting animals employ asynchronous growth pattern of the epithelium.

\section{Introduction}

Growth and movement are two basic proprieties of the animals. The growth patterns of the living organism were reconstructed being through the mechanical analysis of the biological forms [1]. The movement type - peristalsis, is widely employed by the worms living near sediment - water (air) interface, which makes their epithelial system under tension - compression rhythm [2] with relatively high potential energy. Conversely, in the steady state, the cell clusters of the living epithelial cell clusters minimize their potential energy [3].

In a physical perspective, the forms of living beings are driven by movement of the cells. Recent studies quantifying forces in cell proliferation, sorting and other developmental aspects and highlighted that physical force also contribute to maintain boundaries [4-6]. The mechanical properties of the cell lattices have been quantitatively described [7]. Most of the cell boundaries are relatively straight. Comparatively, the leaf epidermal cells with puzzles and pavements of the cell boundary increase the contact area of the neighboring cells and strengthen the structural integrity of the epithelium. The pavement cell form is treating as a phylogenetic signal, the cell shape relates to higher grade anatomical structures and recently pavement cells have been found in the 535 ma worms fossil cuticles [8].

In a larger scale, segments could be regard as periodically organized cell clusters. The segment number varies considerably among species, ranging from six in some frogs to several hundred in snakes. It is known that physical cues, like mechanical stretching can induce the formation of additional somites of the vertebrate embryo [9]. Comparatively, some larva worms add the number of the ring from 80 to more than 300 (the adult form) [10]. The maintenance of straight and sharp boundaries of the segment is crucial for subsequent patterning events. 
Segmentation step wisely evolves in organ systems. Epithelium derives from ectoderm and it can segment normally without the mesoderm [11], suggests an independent regulation pattern of the epithelium segmentation [12]. Segmentation may evolved for improved locomotion in arthropods, annelids and chordates [13].

The early Cycloneuralia with the epithelium segmentation shows remarkable biodiversity of the Cambrian - Ordovician period $[14,15]$. The disparity of the Cycloneuralia falls down after the early Cambrian [16].

\section{Material And Methods}

In this study, the definition of the cell include but not restrict to the biological cell. Two new species of the stem group Cycloneuralia of the early Paleozoic period were reported. The worm fossils surface showing fine polygonal structures which fall into cellular level. Here we use the light microscope Leica 205C and scanning electron microscope to photograph the specimens.

The vertex model was employed to describe cell clusters states within the epithelium of the worms. In the vertex model, the epithelial shape is represented by a set of vertices that mark the common point of three or more neighboring cells. It was initially used to study the packing of bubbles in foams, then adapted to study the 2D packing and rearrangement of apical cell surfaces in the planar epithelium [17].

\section{(a) Image segmentation}

We use the watershed algorithm [18] of Image $\mathrm{J}$ to segment the cells. Initial scanning electron microscope (SEM) images of the worms fossils were smoothed (reduce the noise) to facilitate the cell boundary segmentation.

\section{(b) Cell mechanical analysis}

The processed images were load in the CellFIT to reconstruct the force field of the cell cluster [19]. Cell boundary were generate uniformly spaced mesh points per edge in order to obtain ideal triplet approach angles for calculate forces. A cell is not represented by a polygon, but by a polyarc.

The key equation of CellFIT is for any particular triplet junction to be in equilibrium, the adjacent cell edges satisfy the force balance equation:

$\Sigma \gamma_{\mathrm{mn}} \mathrm{r}_{\mathrm{mnA}}=0$

where the unit vectors $r_{\mathrm{mnA}}$ are constructed tangent to the limiting angle at which the membrane along the boundary between cells $\mathrm{m}$ and $\mathrm{n}$ approaches the triple junction and pointing away from the junction, and the summation is carried out over all edges that connect to triple junction. The $\gamma_{\mathrm{mn}}$ values are the corresponding unknown membrane tensions [19].

The Laplace's equation is used to solve the pressures fields of the system, 
$\Delta \mathrm{p}=\gamma\left(1 / R_{1}+1 / R_{2}\right)$

$\Delta \mathrm{p}$ is the pressure difference between cells. $\gamma$ is the parameter of the surface tension. $\mathrm{R}$ is the radius of curvature of the cells. Base on the equations [19], the tension and pressures fields of the study area of the cell clusters were solved by CellFIT .

\section{Systematic Palaeontology}

\section{Cycloneuralia}

\section{Stem group}

Jinia rosettea gen. et sp. nov.

Etymology. The generic name derives from the the Jindinshan formation, the strata where the fossil been found. Species name after rosette to describe the plate with its surrounding polygons are flower formed (Fig. 1a-d; S1).

Holotype. Guizhou Research Center for Palaeobiology (GRCP) 14001, Guizhou University. GRCP 14002, 14003 represent the developing states of the worms.

Locality and horizon. The specimens were collected from the lower mudstone of the Jindinshan Formation, Cambrian Stage 4, of Guizhou, South China.

Dignosis for genus and species. The body of the worm are made up of rings. Each ring boundary is defined by the annular furrows (Fig. 1b,c; 4a,b; S1). The linear arrange circular plates with apexes distribute on the two sides of the furrow (Fig. 1b; S1g). The furrows are consist of bi-serial oval formed polygons, named boundary cells. The surface of the epidermis dominant by $4-8$ sides cell lattices (Fig. 1d; S1g). The boundary of the plates and cell lattices are zigzag formed (Fig. 1c, d; S1d).

\section{Remarks}

The convergent evolution force several clades fall into a close morph space. The inter plate polygons have been found in the phosphatized epithelial fragments of Hadimopanella which named the micro plates and the boundary cells previously named as inter annular furrows [20,21]. These structures have received less attention than the plate. The small specimens with a relatively narrow inter plate space and the space extends in the larger specimens (Figure S1). The specimen series interpreted as the developmental sequence of the $\mathrm{J}$. rosettea. New inter plate cell lattices emerge (Figure S1). The developmental patterns are widely recorded in other early Cycloneuralia [22].

\section{Meitis elegans gen. et sp. nov.}

Etymology. The generic name derives from the the Meitan formation, the strata that the fossil been found. Species name after elegance. 
Holotype. Guizhou Research Center for Palaeobiology (GRCP) 22001, Guizhou University (Fig. 1e).

Locality and horizon. The specimen was collected from the lower mudstone of the Meitan Formation, Early Ordovician (Florian), Guiyang city, South China.

Dignosis for genus and species. The body of the worm are made up of rings. Each ring boundary defined by the annular furrows (Fig. 1f,g; $4 \mathrm{c}, \mathrm{d}$ ). The annular furrows consist of rectangle polygons. The platelets distribute along the two sides of a row of rectangle polygons. The surface of the epidermis dominant by 6 sides cell lattices (Fig. 1f). The aspect ratio of the plate range from 1-2 and the apexes of the plates range from 1 to 3 (Fig. 1g).

\section{Remarks}

The ornaments of the epidermis of the Ordovician worms [23] occupied a much wider morph spaces than that of their Cambrian counterparts. Meitis elegans gen. et sp. nov. share similarities with the plate outline of the 495-Myr-old Palaeoscolex piscafumm and Gnmoscolex herodes from the lower Ordovician strata. All of them have distinct boundary zone of the rings $[24,25]$. However, the plate apexes and distribution pattern of these species are remarkably different $[24,25]$.

\section{Results}

\section{(a) Comparative anatomy}

Four cuticular elements: plates, platelets, amorphous polygons and linear arrangement polygons are found on the fossil epithelium (Figure 1,2). The shape and size of the cell lattices of the worms are familiar with that of the extant animals epithelial cells (Figure 2a) and the polygons relics could be observed on the inner surface of the cuticles (Figure $S 1 b, c$ ). We tend to treat each polygon fall into a cell grade affinity other than represent subcellular or muticellular ornaments. The linear formed polygons are explained as the boundary cells (BCs) separate each rings. The BCs of J. rosettea are biserial oval formed. Comparatively, BCs of the M. elegans are uniserial rectangle formed (Figure $1 b, g$ ). The J. rosettea epithelium dominant by $4-8$ sides cell lattices (Figure 1c, $d$ ) with zig zag formed boundaries. The cells lattices of $M$. elegans are mainly hexagons and the cell boundaries are relatively straighter (Figure 1g).

\section{(b) Growth and movement pattern reconstruction}

The study quantitatively approach to the growth pattern of the epidermal cell grade structures of the worms being through analysis the force fluctuation landscapes of the cell clusters [26]. Growth and movement process potentially affect the tension and pressure filed of the cells. The tension filed was treat as the proxy to reflect the growth rate within a ring $[26,27]$ (Figure 2). The platelets and plates were regard as developmental continuum in the case of the early worms (Figure $1 g$; Figure $2 b$-d). The developing plate could be regard as a hot spot of tension filed (Figure $2 b-d$ ). Conversely, the cell polygons being the relaxed network configurations (Figure $2 e, f$ ), which represent steady state of the epithelial system of the early molting animals [3]. 
The tension unequally distribute around the worms plates (Figure $2 b-d$ ) which familiar with that of the mitosis loop [28] of the epidermal cells, the new cell proliferating from the hot spot where a relatively high tension value recorded (Figure 2a) [28]. Obviously, the plate has different nature to the mitosis loop and it is not necessary represent a single cell, nevertheless, the nonequilibrium tension fields of the plates suggest they are at the active state. More broadly, the asymmetric distributions of the tension field are found within the mesh like plates of the Microdictyon (Figure 3) [29]. Under the assumption that tension value positive corresponding to the growth rate, the results suggest allometric growth of the early worm epithelium elements.

The pressures are unequally distribute on the two sides of the BCs (Figure $4 b, d$ ), the result suggest boundary cell prevent pressure transmit to adjust region base on the 2D lattices analysis (Figure $4 e$ ). The cells density of BCs region is higher than that of the surrounding cells which resistance to nonequivalent stress field and the tissue under pressure tends towards a uniform cell organization (BCs) [30].

\section{Discussion}

\section{(a) asynchronous growth pattern}

Some clades (tardigrata, onychophora etc.) employed an incomplete molting pattern. Hard epidermal derivatives (jaws, claws, dorsal spines etc.) present corn in corn constructions [31]. The desynchronization molting ensure stiffness of these functional elements (feeding, climbing and protection etc.) all the lifetime. The system tend to relax to the minimum energy state in the plate absent region of the ring (Figure $2 e, f$ ). The developing plates formed like the active islands intersperse among the inactive epithelial cell ocean. Thus we suggest the early worms employ asynchronous growth pattern of the . Simulation experiment reveals the cell type with lower tension will envelop the higher cortical tension cell cluster [32].

The epithelial sheet are 3D in reality, the boundary region of the worm are slightly ingression base on the 3D preserved specimen [14] (Figure S1 $b, c, f$ ). The annuli - furrow patterns were widely employed by worm like animals. Previous work shows differential tension driving epithelial cell ingression [33]. Our results show the consequence of the ingression: The boundary cells prevent pressure transmit to adjust region to established the pressure gradients among rings (Figure 4) which is the basic of worms

peristalsis type movement. The pressure filed was used as the proxy to reflect the movement state among rings.

\section{(b) Topological structure proprieties and development}

The cuticle of the worm is stiff [14], however, the cells underneath the cuticle have relatively lower Yong's modulus [34] which are condensable during the movement of the worm. The puzzle type cell boundaries have multiple re - entrant angles (Figure 1d). The negative poisson's ratio structure [35] would increase the shear modulus [35] of the cell lattices. Thus the Cambrian worm epithelium is more resistant to the shear force and the shape of a cell within tissues can represent the history of physical signals it 
encounters [36]. In the contract and elongation stage of the ring (Figure 4f), the big octagon cells have opposite deformation direction to the small quadrangle cells [37], the anisotropy deform forces may affect cell proliferation events [38] distribution pattern within cell clusters.

The morphology of cells across boundary zones switch dramatically indicate precise label the fate of adjust cell grade structures. The energy - consuming mechanisms governing cell shape. The $4-8$ cell lattices consist of puzzle type cells with negative Poisson's ratio, the structures display hystersis response to strong compression or elongation on the lattices [37]. Both the foam and puzzle type membranes have been employed by modern cells [39]. The foam type cell predominate ensure flexible in bending and facilitate a wide range of reshaping and rearrangement behaviors that are crucial to development and movement of the animals.

The developmental sequence of Jinia suggests an elongation process of the worm rings (Figure S1). In a larger scale, Jinia body elongation should start in the embryonic stages and we treat Markuelia [40] as a model of late embryonic stage of Cycloneuralia, shows each ring approximately 20 micrometers in width which may occupy only two rows of cells [40]. As segments annelids can form from single-cell-wide precursors [9], daughter cells emerge during elongation process of the ring (Figure S1e-g). The rosette pattern being treat as an inter phase of the elongation process [41]. The boundary cells constraint the cell flow within each ring which may explain the rosette pattern formed near the boundary of the ring. Moreover, the boundary cells may promote the fluid-to-solid jamming transition underlies body axis elongation [42].

The study demonstrates the establishment of precise tissue boundary formation of early molting animals through the Cambrian - Early Ordovician period. The subdivision of the elongating body axis into repeated units employed by dozens of phyla [43]. The framework restricts the cell proliferation and force extending in a limited unit, which laying foundation of functional differentiation among and within each unit of the animals body.

\section{Declarations}

\section{Data accessibility}

All fossil specimens from the Jindinshan and Meitan Formation are deposited in the collections of Guizhou Research Center for Palaeobiology, Guizhou University, Guizhou, China.

\section{Funding}

This research is supported by the National Natural Science Foundation of China No.41902003 and Natural Science Foundation of Guizhou No. 20171057.

\section{Acknowledgment}

I thank Jonathan Payne from Stanford University for his advice on the manuscript. 


\section{Competing interests}

The author declares no competing interests.

\section{References}

1. Thompson, D. Arcy W. On growth and form. Cambridge: Univ. Press (1917)

2. Kesidis, G., Slater, B. J., Jensen, S., \& Budd, G. E. (2019). Caught in the act: priapulid burrowers in early Cambrian substrates. Proceedings of the Royal Society B, 286(1894), 20182505.

3. Liang, J., Balachandra, S., Ngo, S., \& O’Brien, L. E. Feedback regulation of steady-state epithelial turnover and organ size. Nature, 548, 588. (2017)

4. Landsberg, K. P., Farhadifar, R., Ranft, J., et al. Increased cell bond tension governs cell sorting at the Drosophila anteroposterior compartment boundary. Current Biology 19, 1950-1955. (2009)

5. Roca-Cusachs, P., Conte, V., \& Trepat, X. Quantifying forces in cell biology. Nature cell biology, 19(7), 742. (2017)

6. Sugimura, K., Lenne, P. F., \& Graner, F. Measuring forces and stresses in situ in living tissues. Development, 143, 186-196. (2016)

7. Staple, D. B., Farhadifar, R., Röper, J. C., et al. (2010) Mechanics and remodelling of cell packings in epithelia. Eur. Phys. J. E 33, 117-127

8. Wang, D., Vannier, J., Yang, X., Sun, J., Sun, Y., Hao, W., Han, J. Cuticular reticulation replicates the pattern of epidermal cells in lowermost Cambrian scalidophoran worms. Proceedings of The Royal Society B: Biological Sciences, 287(1926), 20200470. (2020).

9. Oates, A. C., Morelli, L. G. \& Ares, S. Patterning embryos with oscillations: structure, function and dynamics of the vertebrate segmentation clock. Development, 139, 625-639 (2012)

10. García-Bellido, D. C., Paterson, J. R. \& Edgecombe, G. D. Cambrian palaeoscolecids (Cycloneuralia) from Gondwana and reappraisal of species assigned to Palaeoscolex. Gondwana Research 24, $780-$ 795 (2013)

11. Hannibal, R. L., Price, A. L., \& Patel, N. H. (2012). The functional relationship between ectodermal and mesodermal segmentation in the crustacean, Parhyale hawaiensis. Developmental biology, 361(2), 427-438.

12. Hannibal, R. L., \& Patel, N. H. (2013). What is a segment?. EvoDevo, 4(1), 35.

13. Giangrande, A., \& Gambi, M. C. (1998). Metamerism and life-style within polychaetes: Morphofunctional aspects and evolutionary implications. Italian Journal of Zoology, 65(1), 39-50.

14. Muller, K. J. \& Ingelore, H. Palaeoscolecid worms from the Middle Cambrian of Australia. Palaeontology 36, 549-591 (1993)

15. Wang, W., Muir, L. A., Botting, J. P., Feng, H., Servais, T., \& Li, L. (2014). AT remadocian (E arly O rdovician) palaeoscolecidan worm from graptolitic shales in $\mathrm{H}$ unan $\mathrm{P}$ rovince, $\mathrm{S}$ outh $\mathrm{C}$ hina. Palaeontology, 57(3), 657-671. 
16. Wills, M. A., Gerber, S., Ruta, M., \& Hughes, M. (2012). The disparity of priapulid, archaeopriapulid and palaeoscolecid worms in the light of new data. Journal of evolutionary biology, 25(10), 2056-2076.

17. Fletcher, A. G., Osterfield, M., Baker, R. E., et al. Vertex models of epithelial morphogenesis. Biophysical journal 106, 2291-2304 (2014)

18. Grady, L. (2006). Random walks for image segmentation. IEEE Transactions on Pattern Analysis \& Machine Intelligence, (11), 1768-1783.

19. Brodland, G. W., Veldhuis, J. H., Kim, S., et al. CellFIT: a cellular force-inference toolkit using curvilinear cell boundaries. PLoS One 9, e99116 (2014)

20. Bendix-Almgreen, Svend E., and John S. Peel. Hadimopanella from the Lower Cambrian of North Greenland: Structure and Affinities. 1988.

21. Topper, T. P., Brock, G. A., Skovsted, C. B., \& Paterson, J. R. (2010). Palaeoscolecid scleritome fragments with Hadimopanella plates from the early Cambrian of South Australia. Geological Magazine, 147 (1), 86-97.

22. Liu Y, Wang Q, Shao T, et al. New material of three-dimensionally phosphatized and microscopic cycloneuralians from the Cambrian Paibian Stage of South China. Journal of Paleontology, 92: 8798. (2018)

23. Botting, J. P., Muir, L. A., Van Roy, P., Bates, D., \& Upton, C. (2012). Diverse middle Ordovician palaeoscolecidan worms from the Builth-Llandrindod Inlier of central Wales. Palaeontology, 55(3), 501-528.

24. Conway Morris, S. The cuticular structure of the 495-Myr-old type species of the fossil worm Palaeoscolex, P. piscatorum (? Priapulida). Zoological Journal of the Linnean Society, 119, 69-82 (1997)

25. Hinz, I. , Kraft, P. , Mergl, M. , \& KLAUS J. MüLLER. (2010). The problematic hadimopanella, kaimenella, milaculum and utahphospha identified as sclerites of palaeoscolecida. Lethaia, 23 (2), 217-221.

26. Sugimura, K., Lenne, P. F., \& Graner, F. Measuring forces and stresses in situ in living tissues. Development, 143, 186-196. (2016)

27. Kong, W. , Loison, O. , Shivakumar, P. C. , Chan, H. Y. , \& Raphal Clément. (2019). Experimental validation of force inference in epithelia from cell to tissue scale. entific Reports, 9(1).

28. Gibson, M. C., Patel, A. B., Nagpal, R., et al. The emergence of geometric order in proliferating metazoan epithelia. Nature 442, 1038-1041 (2006)

29. Zhang, X. G., \& Aldridge, R. J. Development and diversification of trunk plates of the Lower Cambrian lobopodians. Palaeontology, 50, 401-415. (2007)

30. Marinari, E., Mehonic, A., Curran, S., Gale, J., Duke, T., \& Baum, B. (2012). Live-cell delamination counterbalances epithelial growth to limit tissue overcrowding. Nature, 484, 542.

31. Caron, J. B., Smith, M. R., \& Harvey, T. H. (2013). Beyond the Burgess Shale: Cambrian microfossils track the rise and fall of hallucigeniid lobopodians. Proceedings of the Royal Society of London B: 
Biological Sciences, 280 (1767), 20131613.

32. Heer, N. C. \& Martin, A. C. Tension, contraction and tissue morphogenesis. Development 144, 42494260 (2017)

33. Lee, J. Y. \& Goldstein, B. Mechanisms of cell positioning during C. elegans gastrulation. Development $130,307-320$ (2003)

34. Yang, C., Tibbitt, M. W., Basta, L., \& Anseth, K. S. Mechanical memory and dosing influence stem cell fate. Nature materials, 13, 645. (2014)

35. Saxena, K. K., Das, R., \& Calius, E. P. Three decades of auxetics research - materials with negative Poisson's ratio: a review. Advanced Engineering Materials, 18, 1847-1870. (2016)

36. Ron, A., Azeloglu, E. U., Calizo, R. C.,et al. Cell shape information is transduced through tensionindependent mechanisms. Nature communications, 8, 2145. (2017)

37. Florijn, B., Coulais, C., \& van Hecke, M. Programmable mechanical metamaterials. Physical review letters, 113, 175503 (2014)

38. LeGoff, L., Rouault, H., \& Lecuit, T. A global pattern of mechanical stress polarizes cell divisions and cell shape in the growing Drosophila wing disc. Development, 140, 4051-4059. (2013)

39. Carter, R., Sánchez-Corrales, Y. E., Hartley, M., et al. Pavement cells and the topology puzzle. Development 144, 4386-4397 (2017)

40. Dong, X. P., Bengtson, S., Gostling, N. J., Cunningham, J. A., Harvey, T. H., Kouchinsky, A., ... \& Donoghue, P. C. (2010). The anatomy, taphonomy, taxonomy and systematic affinity of Markuelia: Early Cambrian to Early Ordovician scalidophorans. Palaeontology, 53(6), 1291-1314.

41. Tetley, R. J., \& Mao, Y. (2018). The same but different: cell intercalation as a driver of tissue deformation and fluidity. Phil. Trans. R. Soc. B, 373(1759), 20170328.

42. Mongera, A., Rowghanian, P., Gustafson, H. J., Shelton, E., Kealhofer, D. A., Carn, E. K., ... \& Campàs, 0. (2018). A fluid-to-solid jamming transition underlies vertebrate body axis elongation. Nature, 561(7723), 401.

43. Davis, G. K. \& Patel, N. H. The origin and evolution of segmentation.Trends in Genetics $15,68-72$ (1999)

\section{Figures}




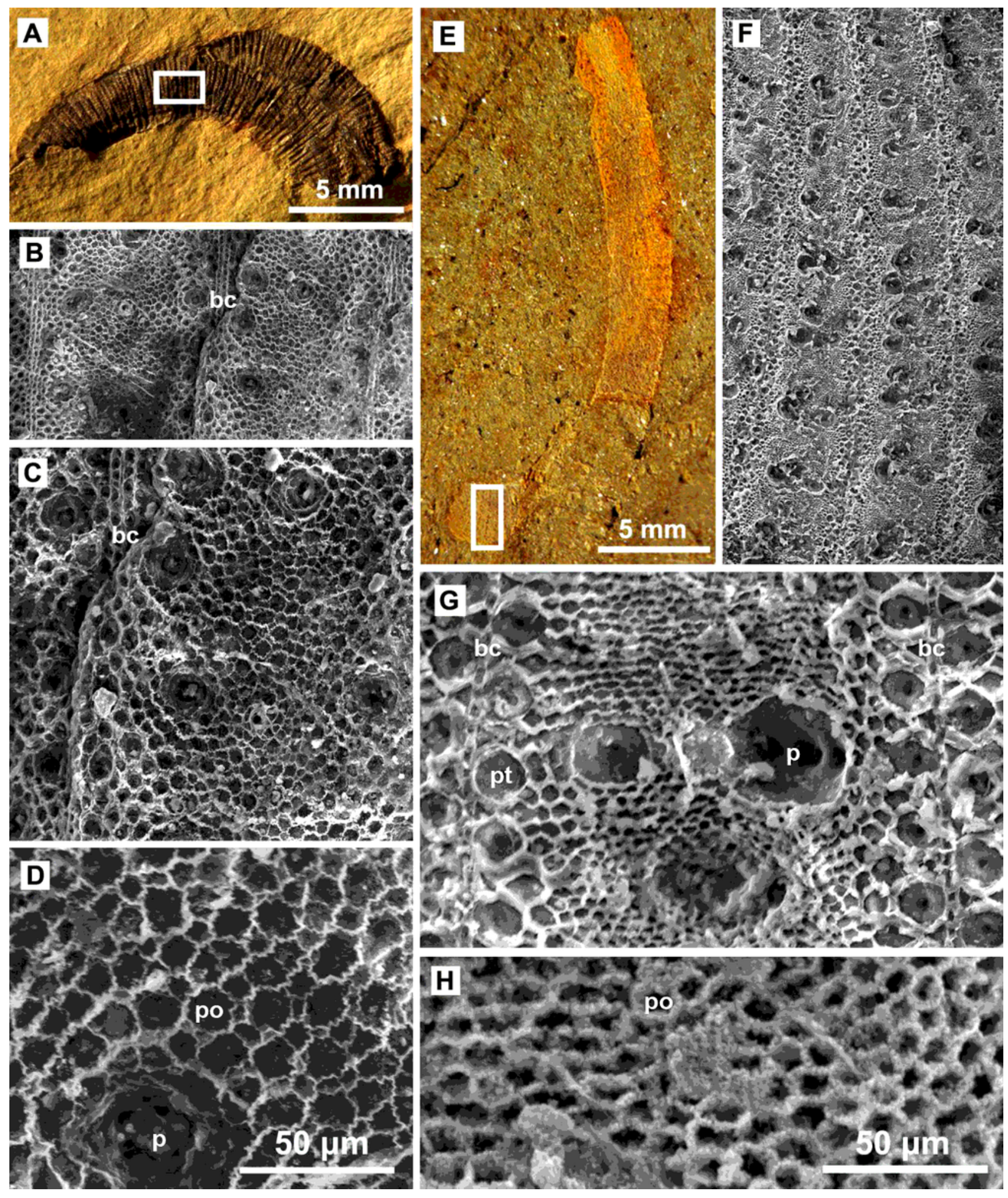

Figure 1

Early worms epithelium. A-D GRCP 14001, Jinia rosettea gen. et sp. nov. from Cambrian Stage 4 (515 $\mathrm{ma}) ; B$, zoom in of the square frame of $A ; C$, zoom in of the epithelium overlapping region of $B ; D$, zoom in of the 4-8 sides puzzle-type polygons; E-H GRCP 22001, Meitis elegans gen. et sp. nov. from Early Ordovician, Florian (470 ma). F, zoom in on the square frame of E. G, zoom in on a body unit of the worm, 
showing 6 sides polygons and plates separated by tiny linear boundary cells; $H, 6$ sides polygons, some of which elongated along AP axis. Abbreviation: bc: boundary cell; p: plate; po: polygon; pt: platelet.
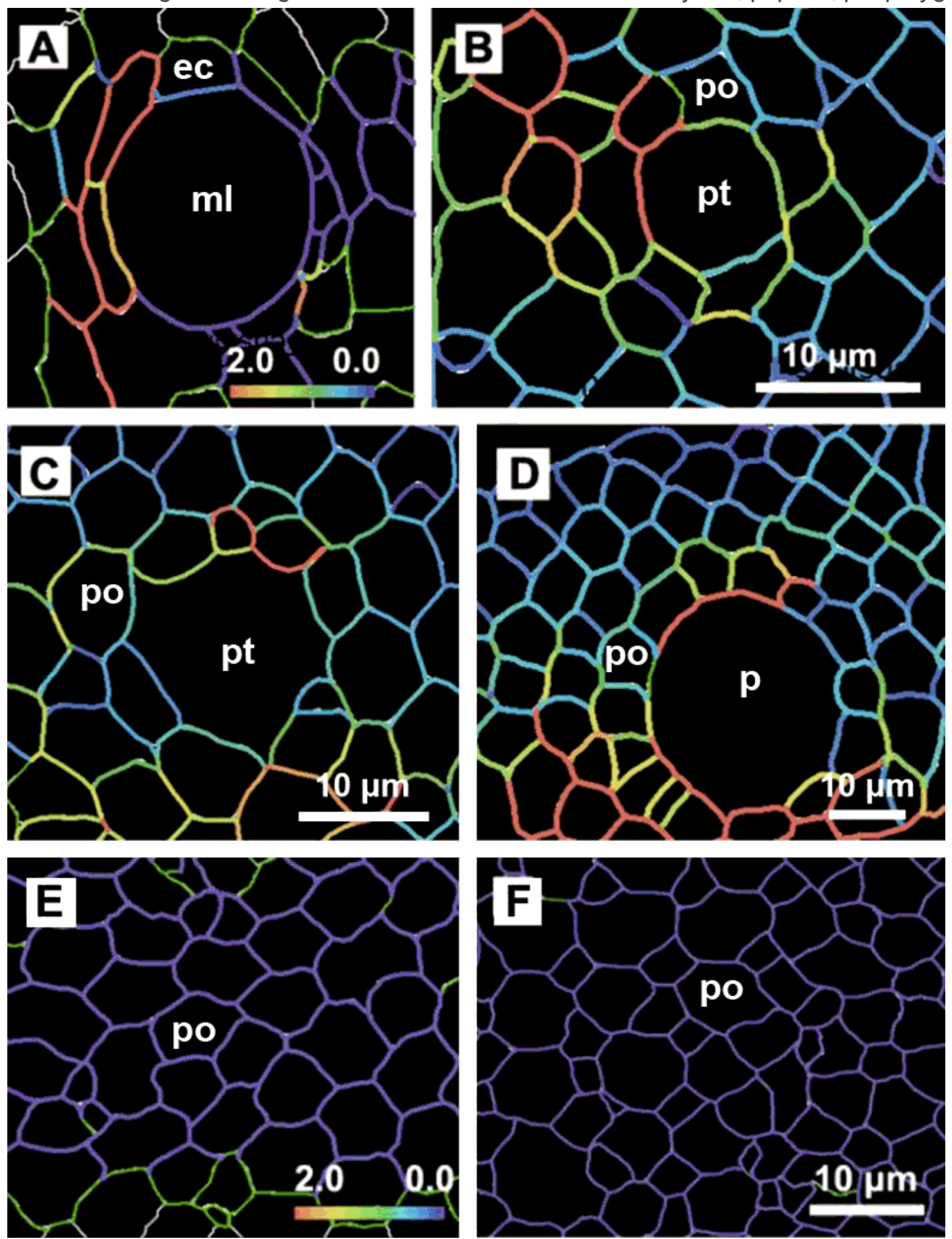

Figure 2

The relative tension field of extant and extinct animals epithelium. A, The excited state of the tension field of mitosis loop of the extant animals epidermal cells28 and B-D the excited state of the tension field around the plate of Jinia rosettea. E, The ground state of the tension field of the generalize epidermal 
cells of the Meitis elegans and F, J. rosettea. Abbreviation: ec: epithelial cell; ml: mitosis loop; p: plate; po: polygon; pt: platelet.

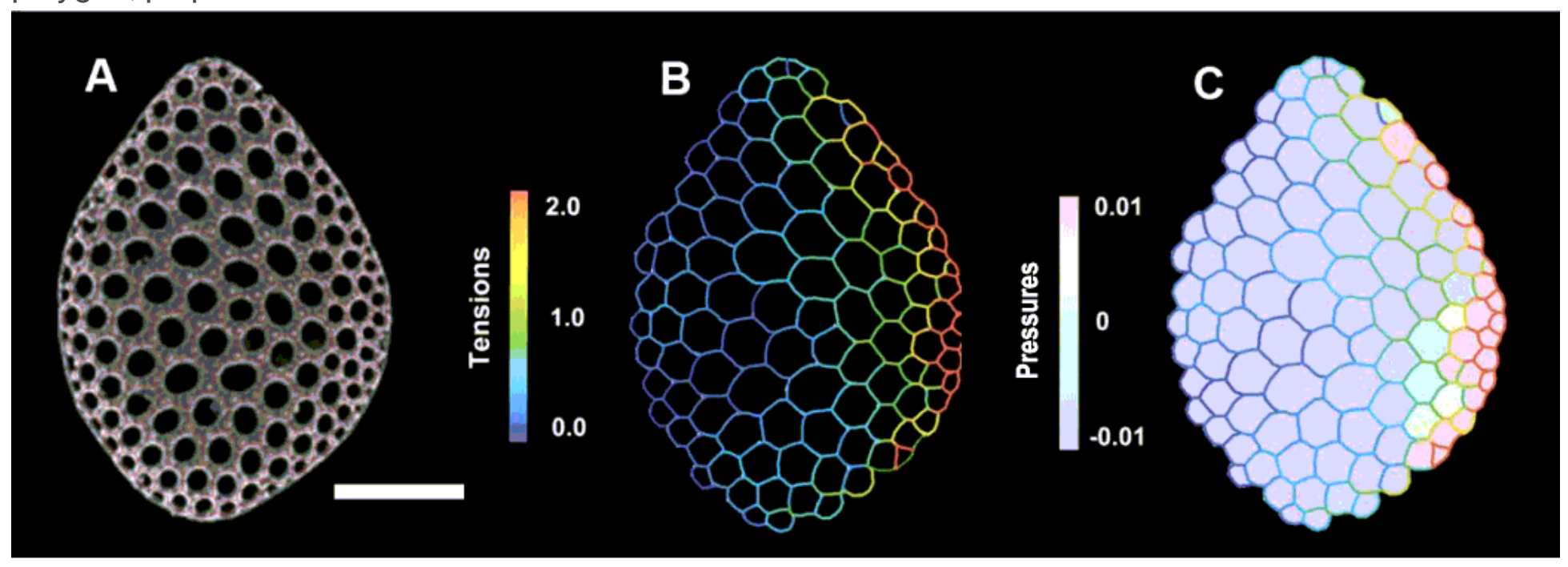

\section{Figure 3}

The relative tension field of extant and extinct animals epithelium. A, The excited state of the tension field of mitosis loop of the extant animals epidermal cells 28 and B-D the excited state of the tension field around the plate of Jinia rosettea. $E$, The ground state of the tension field of the generalize epidermal cells of the Meitis elegans and F, J. rosettea. Abbreviation: ec: epithelial cell; ml: mitosis loop; p: plate; po: polygon; pt: platelet. 


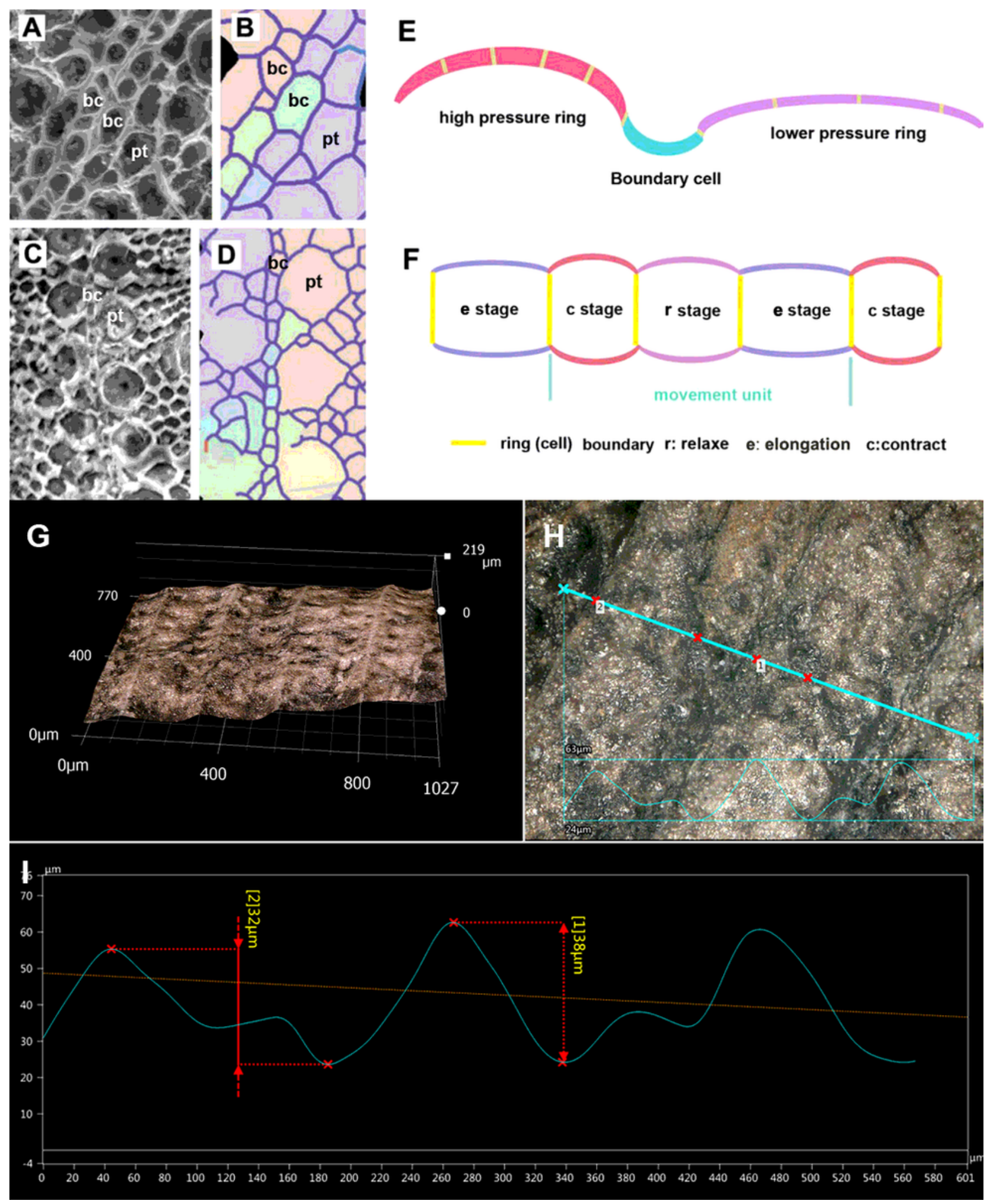

\section{Figure 4}

The relative stress field of the boundary cells (BCs) region of the worms epithelium and their movement model. A-B, Jinia rosettea; $C-D$, Meitis elegans; $E$, sagittal plane sketch of the worm showing boundary cell maintain potential energy barrier between two rings; $F$, simplified peristalsis movement model of the worms. $\mathrm{G}$, the hologram of $\mathrm{J}$. rosettea; $\mathrm{H}$, I, the elevation landscape of the ring of $\mathrm{J}$. rosettea. Abbreviation: bc: boundary cell; pt: platelet. 


\section{Supplementary Files}

This is a list of supplementary files associated with this preprint. Click to download.

- Supplementalinformation.docx 